551. 508. $85: 621.369 .9$

\title{
Radar Performance of the Precipitation Echoes Employing a Logarithmic I. F. Amplifier and an Averaging Device
}

\author{
by \\ N. Kodaira \\ Meteorological Research Institute, Tokyo \\ (Received October 5, 1959)
}

\begin{abstract}
The random fluctuations of the weather signals about the average value limit the accuracy of the information obtained from the signals. The averaged echo intensity will indicate a more accurate value than the non-averaged signal. This paper describes the probability distribution of the averaged signal from the logarithmic I.F. amplifier indicating the relation of the averaged value, the peak value and the calculated value from the radar equation. The instrument which produces an averaged iso-echo contouring PPI using a quartz delay line is briefly mentioned.
\end{abstract}

\section{Introduction}

The problem of measuring weather radar echo intensity has been studied for many years. The echoes from precipitation are composed of a huge number of raindrops and the transitions of their relative position cause noisy fluctuation of the echo amplitude. Because of the fluctuating nature of precipitation echoes, it is clear that the averaged echo intensity will indicate a more accurate value than the non-averaged signal. The dynamic range of echo intensity is usually very wide, so measurements in terms of logarithmic level are often preferred.

The received field strength from a precipitation particle will be in the form

$$
r=r(t) e^{-j \varphi(t)} \text {. }
$$

As only the echo from a given target area, at a given range, is of interest, $r$ and $\varphi$ in this equation will be functions of of time.

Total received power $P$ will be the power of received field strength $\boldsymbol{R}$ which is the vector sum of individual field strength

$$
P=\boldsymbol{R}^{2}=\left(\sum_{i} \boldsymbol{r}_{i}\right)^{2}
$$

The reflected power $P_{0}$ calculated from radar equation which is proportional to the radar reflectivity $Z$ at a given range is the sum of $P_{i}$, the received power from an 
individual precipitation particle,

$$
P_{0}=\sum_{i} P_{i}=\sum_{i} r_{i}{ }^{2}
$$

It will be worth while to clarify the relation of $P_{0}$ and $P$, because they are not always equal to each other.

The following items for the precipitation echoes can be assumed:

1) The pulse duration is short and $r$ and $\varphi$ will be constant but they will still vary from one sweep to another. Although $r$ and $\varphi$ are thus defined only a discrete time, that are multiples of the repetition period, they will still be considered as continuous functions of time.

2) There are a very large number of precipitation particles that will contribute to the echo strength in the target volume. For the usual weather radar, precipitation will always fulfil this assumption.

3) The positions of the individual precipitation particles are at random, and thus the phases of the component echoes must be equally probable,

$$
\bar{x}_{i}=\bar{y}_{i}=0 .
$$

4) The probability of receiving an echo from a target is independent of the echo from other targets.

Under these conditions, yielding the results of the probability distribution $W(P)$ of the echoes from precipitation which may be expected from a large number of targets in random positions computed theoretically (LAwson, Austin, WaLlace), $W(P)$ will be expressed in the form of Rayleigh distribution,

$$
W(P) d P=\frac{1}{\bar{P}_{0}} e^{-\frac{P}{\bar{P}_{0}}} d P
$$

where $\bar{P}_{0}$ is the average of $P_{0}$. The experiments (AUSTIN) show fairly good agreement with the theory.

This probability distribution is independent of the distribution of the component distribution, providing that there are a large number of targets and that they are stationary in time.

\section{Probability distribution of intensity in logarithm}

Providing that a logarithmic I. F. receiver is used, the output power $\xi$ will be proportional to $\log P$, and the probability distribution is

$$
W(\xi) d \xi=\frac{1}{M \bar{P}_{0}} \exp \left(-\frac{e^{\xi / M}}{\bar{P}_{0}}+\frac{\xi}{M}\right) d \xi
$$

where $M=1 / 2.3026$. For the convenience of calculation, a normalized value is used, and then

$$
W\left(\xi_{0}\right) d \xi_{0}=\frac{1}{M} \exp \left(-e^{\frac{\xi_{0}}{M}}+\frac{\xi_{0}}{M}\right) d \xi_{0},
$$


where $\xi_{0}=\log \frac{P}{\overline{P_{0}}}$ and is shown in Fig. 1 .

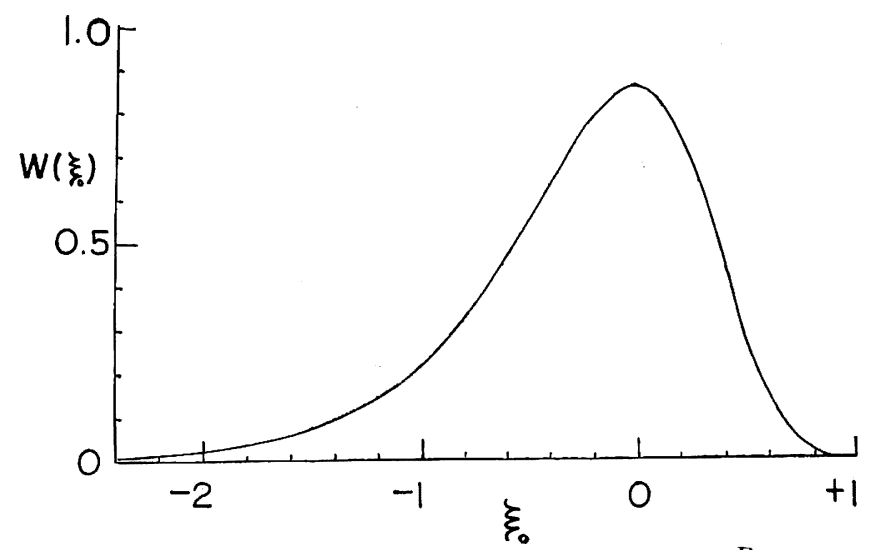

Fig. 1. Probability distribution of $\xi_{0}=\log \frac{P}{P_{0}}$.

The average value of $\xi_{0}$ is given by integrating $\xi_{0} W\left(\xi_{0}\right)$,

$$
\overline{\xi_{0}}=\overline{\log \frac{P}{\bar{P}_{0}}}=\int \xi_{0} W\left(\xi_{0}\right) d \xi_{0}=-M \cdot \gamma
$$

where $\gamma=0.577$. The observed power of $\overline{\log P}$ is about $2.5 \mathrm{db}$ below the calculated power of $\log \overline{P_{0}}$.

In the contour mapping device (KodAIRA) is employed a level setting circuit in which only the signal above the predetermined level $L$ is shown on the PPI screen. The probability $W_{L}\left(\xi_{0} \geqq L\right)$ that the signal will appear on PPI is

$$
\begin{aligned}
& W_{L}\left(\xi_{0} \geqq L\right) d \xi_{0}=\int_{\xi_{0}=L}^{\infty} \frac{1}{M} \times \\
& \exp \left(\frac{\xi_{0}}{M}-e^{\frac{\xi_{0}}{M}}\right) d \xi_{0}=\exp \left(-e^{\frac{L}{M}}\right) .
\end{aligned}
$$

The relation between $W_{L}$ and $L$ is shown by the curve 1 in Fig. 5 .

The comparison of this relationship by the contouring device and the averaged value measured by Pulse Integrator (Williams) is shown in Fig. 2. The peak value measurements are made at the level where the signals will begin to appear on $R$-scope. Since the

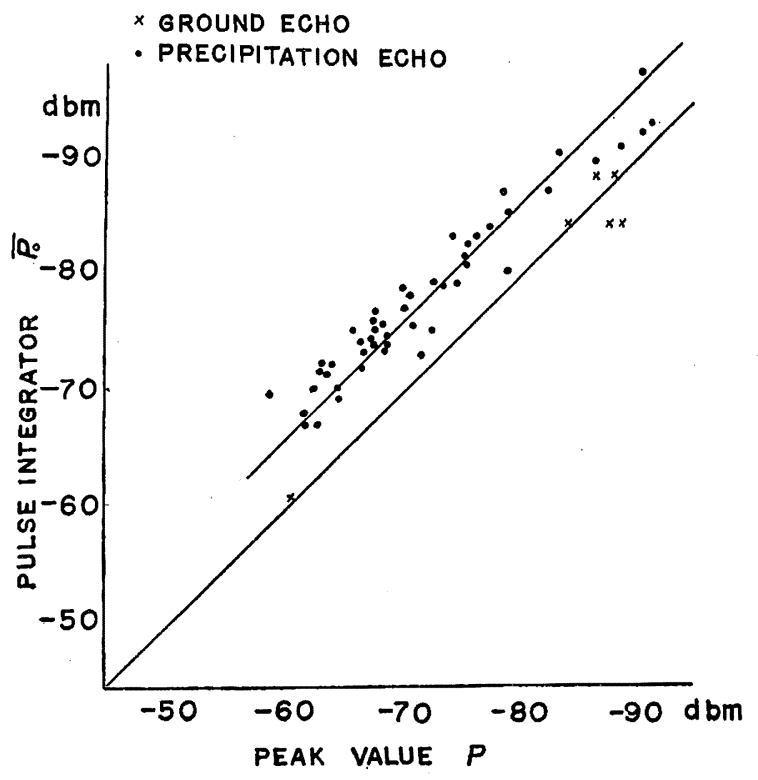

Fig. 2. Comparison of peak values with averaged values for the precipitation echoes and ground echoes. 
measurements of the echo intensity by Pulse-Integrator has been made averaging a very large number of samples from a linear receiver, and the average value of equation (1) is $\bar{P}_{0}$, the results may indicate the value of this average $\bar{P}_{0}$.

The ground echoes in Fig. 2 appear on the same level in both measurements because they are not composed of many targets distributed at random but may be fixed objects and their echoes will be steady and do not show fluctuations.

The threshold characteristics of the leveling circuit in which only signals above a certain level will feed through, show that the output signal will saturate about $2 \mathrm{db}$ higher than the weakest signal. Accordingly, the measurements of peak values may be performed at the level where a few tenths of total signals appear on the scope.

The difference between $\log \bar{P}_{0}$ and $\log P$ in Fig. 2 is about $6 \mathrm{db}$. From Fig. 5 , $6 \mathrm{db}$ higher than $\bar{P}_{0}$ for the curve $m=1$ means that the peak values are determined, in this case, at the level where about $2 \%$ of total signals are detected on the scope. The difference between $\bar{P}_{0}$ and $P$ seems to become smaller when the signal weakens to around $-90 \mathrm{dbm}$. This may be caused by the calibrating pulse of the signal generator which has a flat top when it is strong enough but is accompanied by a noisy fluctuating top as it comes to a smaller value. In the region of the calibration by the noisy top pulse, the difference between $\bar{P}_{0}$ and $P$ will be smaller than in the flat top region.

\section{Probability distribution for the averaged intensity in logarithm}

The iso-echo contours obtained directly from the received signals have random fluctuation and the determination of echo intensity will be accompanied with some uncertainty. It is clear that the averaged signal can produce more accurate contours. When a linear receiver is used, the probability distribution of equation (1) may be calculated for the averaged value of $k$ independent samples and given by, (W ALLACE)

$$
W\left(J_{k}\right) d J_{k}=\frac{k^{k}}{\left(\bar{P}_{0}\right)^{k}(k-1) !} J_{k}^{k-1} e^{-\frac{k J_{k}}{\bar{P}_{0}}} d J_{k} .
$$

To calculate the probability distribution for the averaged value of logarithmically compressed video signal, the equation $\left(2^{\prime}\right)$ cannot be integrated as in the case of linear reception. However, it is possible if the exponential function $\left(2^{\prime}\right)$ is approximated, over the range of values of interests by the following function:

$$
F(\xi)=K e^{a \xi-b}(a \xi-b)^{2}, \quad-\infty<\xi \leqq \frac{b}{a} .
$$

This requires a suitable choice of the coefficients $K, a$ and $b$.

Choosing these coefficients by the following conditions:

a) As this function should be also a probability distribution function, the integration over the whole range will become unity.

$$
\int_{-\infty}^{b / a} K e^{a \xi-b}(a \xi-b)^{2} d \xi=\frac{2 K}{a}=1 .
$$

b) The maximum value is equal to the original function of 0.845 . 


$$
F(\xi)_{\max }=F\left(\frac{b-2}{a} ;=0.54 K=0.845\right. \text {. }
$$

c) The mean value is also equal to the original function of $-M \cdot \gamma$.

$$
\int_{-\infty}^{b / a} \xi K e^{a \xi-b}(a \xi-b)^{2} d \xi=\frac{2 K}{a^{2}}(b-3)=-M \cdot \gamma
$$

then the coefficients will be

$$
K=1.565 \quad a=3.13 \quad b=2.215 .
$$

Plots of the comparison of this approximation with the original function are shown in Fig. 3.

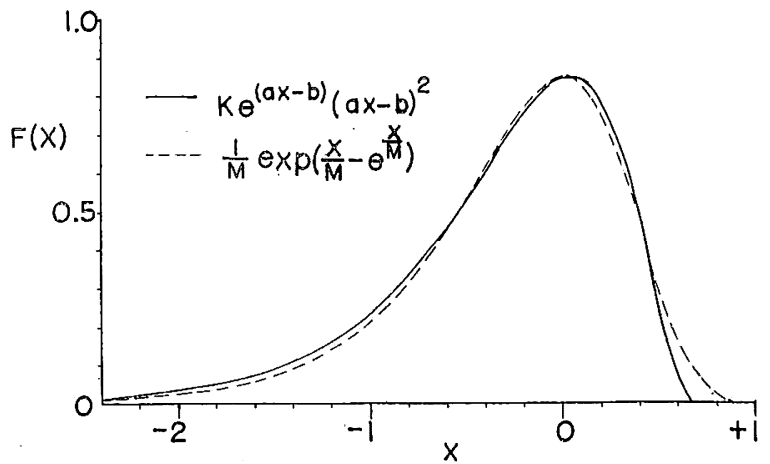

Fig. 3. Comparison of the approximated function with the original function.

Using this approximation, the probability distribution of the averaged case is calculated by the Fourier transform $\varphi(\omega)$ of the function $F(\xi)$,

$$
\varphi_{i}(\omega)=\int_{-\infty}^{b / a} K e^{a \xi-b}(a \xi-b)^{2} e^{j \xi \omega} d \xi=2 a^{2} K \frac{e^{j \omega b / a}}{(a+j \omega)^{3}} .
$$

The average of $m$ independent intensity values $F_{m}(\eta)$ is

$$
\begin{aligned}
F_{m}(\eta) d \eta & =\frac{1}{2 \pi} d \eta \int_{-\infty}^{\infty} \varphi_{1}(\omega) \varphi_{2}(\omega) \cdots \cdots \varphi_{m}(\omega) e^{-j \eta \omega} d \omega \\
& =\frac{(2 K)^{m}}{a^{m-1}} \frac{(m b-a \eta)^{3 m-1}}{(3 m-1) !} e^{-(m b-a \eta)} d \eta
\end{aligned}
$$

where $\eta=\sum_{1}^{m} \xi=m J_{m}$ and $\frac{2 K}{a}=1$ then,

$$
F_{m}(\eta) d \eta=\frac{m a\left\{m\left(b-a J_{m}\right)\right\}^{3 m-1}}{(3 m-1) !} e^{-\left(b-a J_{m}\right)^{m}} d J_{m} .
$$

This corresponds to the linearly averaged distribution of equation (5).

Graphs of the distribution $J_{m}$ for $m=1,5,10,20,50$ are shown in Fig. 4. These curves are concerned with independent data. The correlation between two adjacent signals will become nearly zero when the time interval between the signals is more 
than $0.01-0.02$ second (Stone \& Fleisher). This time interval $T_{0}$ depends on the movement of individual precipitation particles within the volume of space illuminated by the radar transmitter. Because the present instrument has a p.r.f. of $400 \mathrm{cps}$. and a wave length of $10 \mathrm{~cm}$, adjacent video signals are not completely independent as their time interval $t$ is 0.0025 second. This will affect the averaging number by a factor $\alpha$, which will have a magnitude between 1 and $t / T_{0}$.

The bandwidth of the receiving set or the video amplifier also affects the averaging number by a factor $\beta$ because of the space average is carried on. The video signal will feed through the delay line and I.F. amplifier $n$-times for averaging, the over-all band-pass characteristics will depend on the number of addition $n$ in the averaging circuit.

Table 1 indicates the effective bandwidth $B$, the number $n$ and the bandwidth factor $\beta=1 / B \cdot \tau$ where $\tau$ is the pulse width of the radar. The bandwidth is measured by investigating the wave shape after feeding a rectangular video signal through the delay line and accompanied I.F. amplifier circuits $n$-times.

The effective number of integration $m$ is therefore

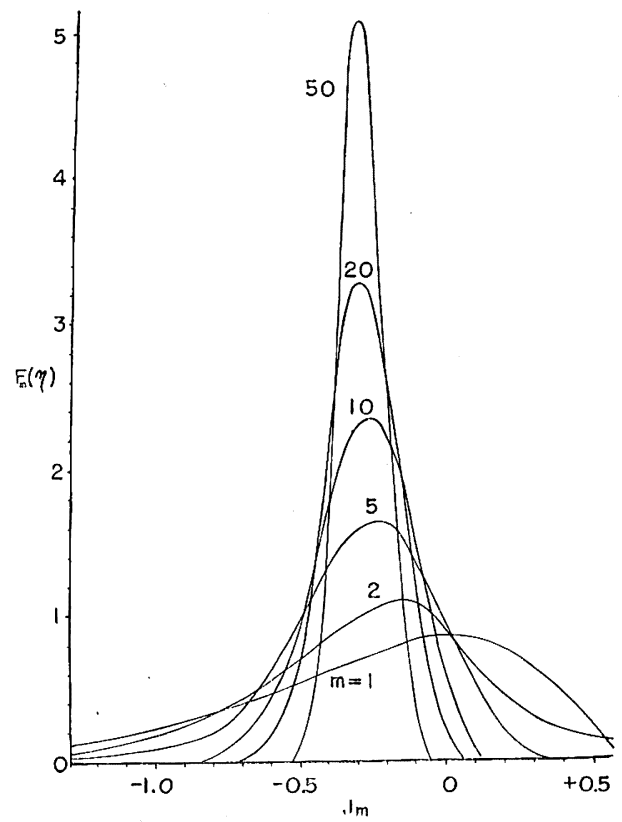

Fig. 4. Probability distribution of $J_{m}$, the average of $m$ independent values of logarithmic signal intensity $\xi_{0}$.

Table 1. Averaging number $n$, bandwidth $B$ and bandwidth factor $\beta$.

\begin{tabular}{rcc}
\hline$n$ & $B$ & $\beta$ \\
\hline 5 & 0.35 & 2.4 \\
10 & 0.23 & 3.6 \\
25 & 0.22 & 3.8
\end{tabular}

$$
m=n \cdot \alpha \cdot \beta .
$$

The threshold level of the contour mapping device which employs averaged video signals will be determined by

$$
\begin{aligned}
W_{L}\left(J_{m} \geqq L\right) d J_{m} & =\int_{L}^{b \mid a} \frac{m a\left\{m\left(b-a J_{m}\right)\right\}^{3 m-1}}{(3 m-1) !} e^{-\left(b-a J_{m}\right) m} d J_{m} \\
& =1-m^{3 m-1} e^{-m(b-a L)} \sum_{r=0}^{3 m-1} \frac{(b-a L)^{3 m-1-r}}{(3 m-1-r) ! m^{r}}
\end{aligned}
$$

Fig. 5 shows this equation for $m=1,2,5,10,40$. Fig. 6 is the plot of the limits below which 10 and $90 \%$ of the averages of $m$-independent measurements of $\xi_{0}$ may be expected to fall. 


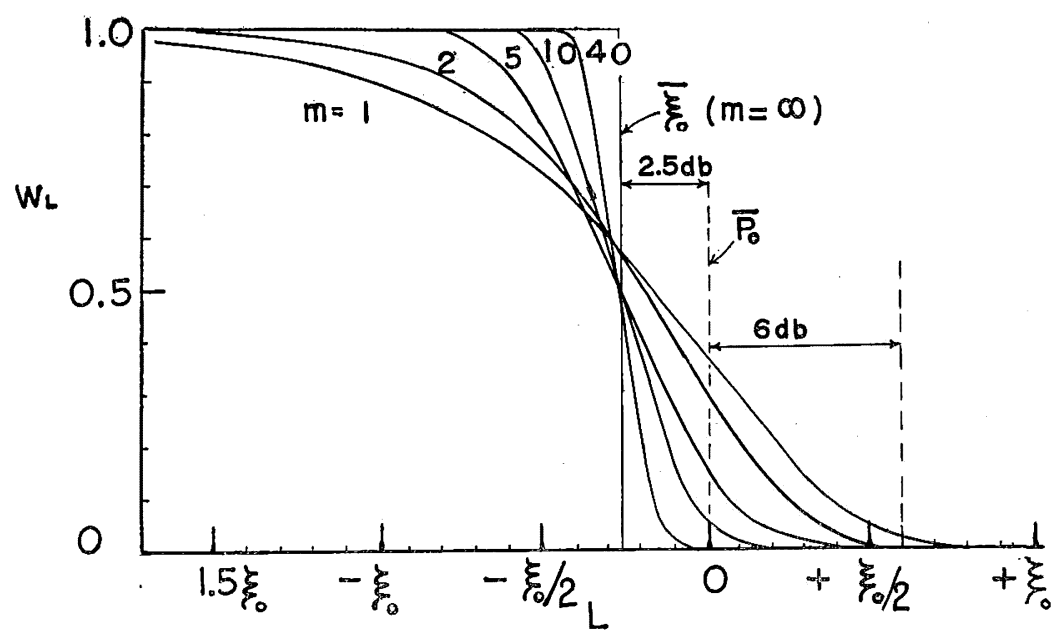

Fig. 5. Probability that the signal above level $L$ will appear on the scope.

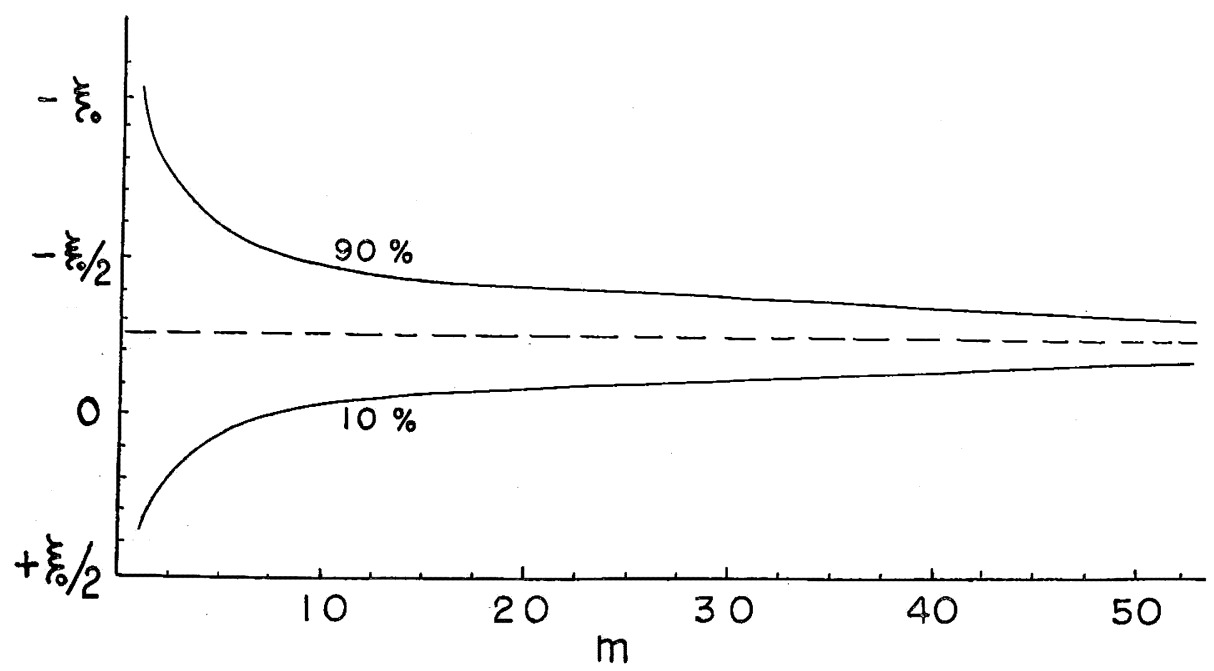

Fig. 6. Width of the distribution of averages of $m$ independent values of $\xi_{0}$, indicating that 10 to $90 \%$ of the average of signal intensity may be expected to fall between these two lines.

\section{Description of the circuit}

The function of the instrument is to sum up successive video signals after delaying them using a quartz delay line. The main components of the instrument are shown in the block diagram in Fig. 7. The radar video signal from a logarithmic I.F. amplifier is first changed to a 20 M.C. amplitude modulated I.F. signal and fed to a quartz delay line, which has a delay time of 2500 microseconds, main attenuation of $44 \mathrm{db}$, a spurious response of $-44 \mathrm{db}$ and a center carrier frequency of $20 \mathrm{M}$.C. The spurjous signal produced in the delay line is $44 \mathrm{db}$ below the signal, but, since the echoes from nearby buildings and ground are very strong, their 
spurious signal may interfere with the output signals especially when the integrating number is large. The integrating number is mainly limited by this spurious signal.

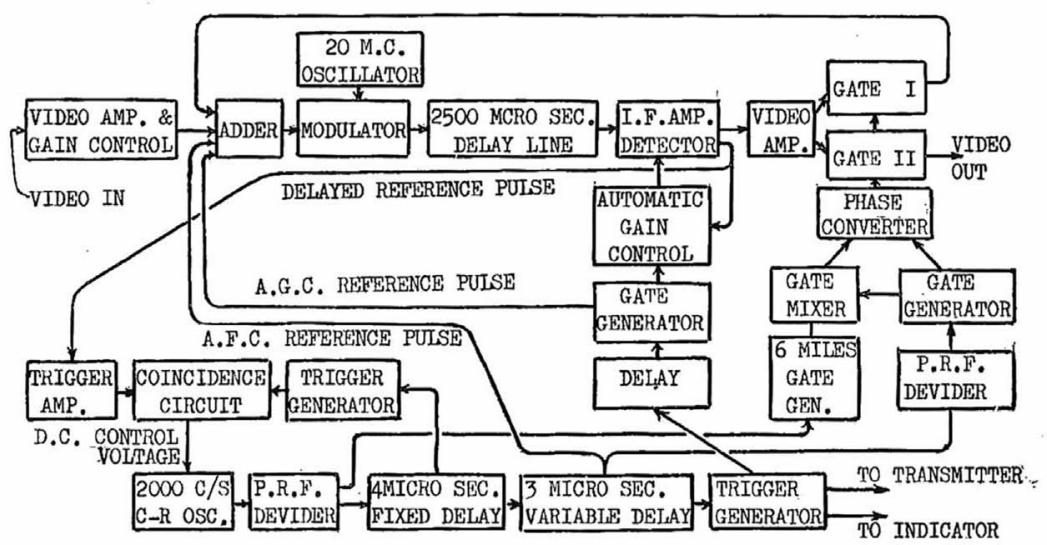

Fig. 7. Block diagram of the averaging device.

After passing through the quartz delay line, having been attenuated about 44 $\mathrm{db}$, the signals are amplified by a linear I.F. amplifier and demodulated to get video signals delayed by 2500 microseconds, which is one period of the transmitting pulse train.

These delayed video signals are fed back to the adder circuit and added to the next video signals. The process is continued and video signals are integrated until gate $I$ is closed to stop the video signals from going to the adder circuit and gate II is opened to feed the integrated video signals to the level and contouring circuit. The pulse recurrence period should be exactly the same as the delay time of 2500 microseconds, by the accuracy of the order of the fraction of pulse width. Otherwise the video signals will not be integrated but displaced with respect to each other by the interval of the difference between delay time and pulse recurrence period. For this control of p.r.f., a reference pulse and a coincidence pulse, one of which goes through the delay line, are compared at the coincidence circuit.

\section{Results}

Fig. 8 is the $R$-scope of rain echoes showing the effect of integration. PPI display of these video signals after range correction and contouring circuits are shown in Fig. 9.

The probability distribution of $J_{n}$, the average

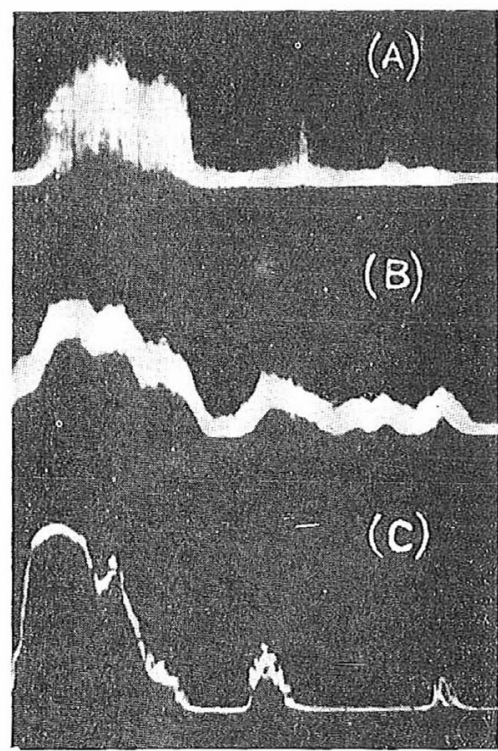

Fig. 8. R-scope of precipitation echoes showing the effect of integration. A) original video signal, B) the integrated video signal when $n=10$, C) $n=25$. 


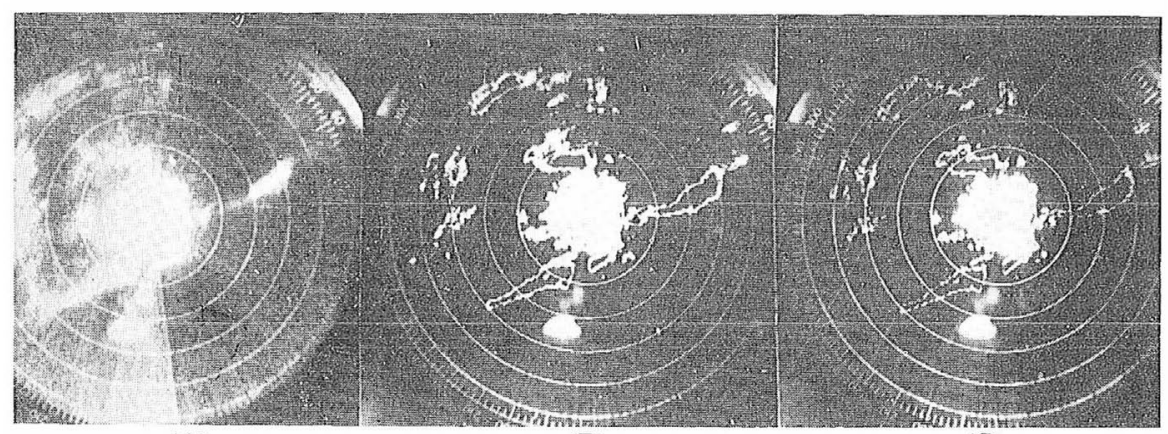

(A)

(B)

(C)

Fig. 9. PPI photograph of precipitation echoes on Nov. 30, 1957, showing the effect of integrated contours, A) normal PPI, B) contours by integrated video signals $n=10 \quad$ C) $n=25$.

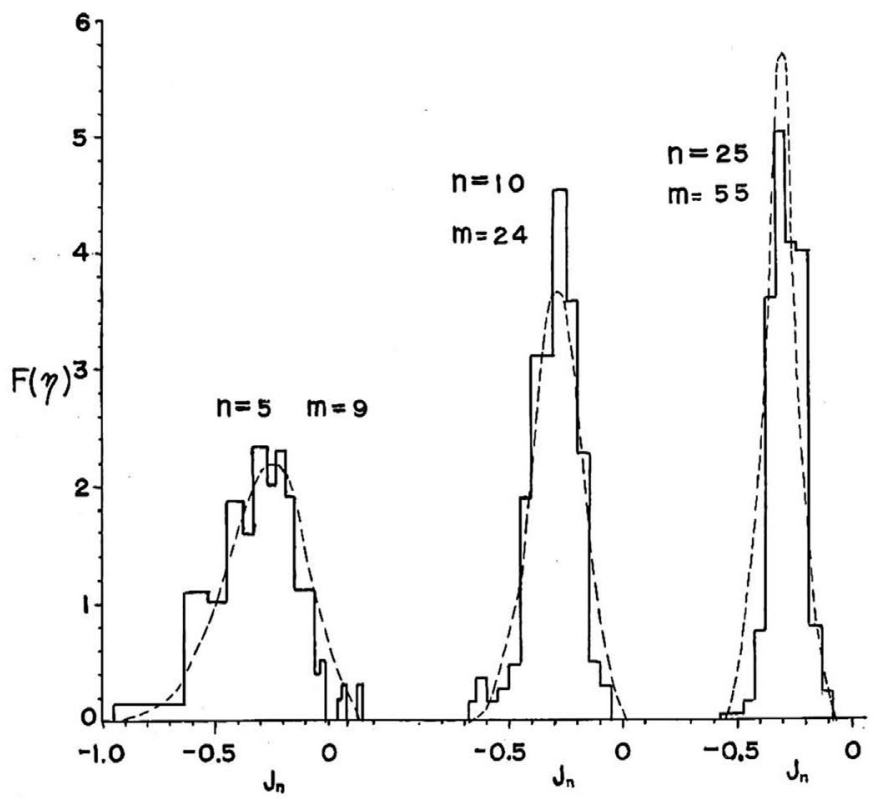

Fig. 10. Probability distribution of the averaged intensity for precipitation echoes with $n=5,10,25$. The dotted lines are the theoretical curves based on the function (8) and having the same standard deviation.

of $n$ samples of the signal, is shown in Fig. 10. These measurements are made by taking successive $R$-scope photographs of steady precipitation echoes, each photograph contains several traces of echoes and their intensities can be measured individually. The dotted lines in Fig. 10 are the theoretical values based on equation (8), the average of $m$ independent intensity, and has the same standard deviation to the probability distribution of the average of $n$ samples.

The factor $\alpha$, as described in section 3 , is determined by the nature of the movement of individual precipitation particles and estimated at $1>\alpha>0.25 \sim 0.12$ for $10 \mathrm{~cm}$ and 400 p.r.f. radar. From the comparison of measured and theoretical values 
of integrating number $n$ and $m$, the factor $\alpha$ can be estimated by equation (9) as shown in Table 2.

The factor $\alpha$ lies between the value expected from the time interval $T_{0}$. However, because of the smallness of sampling number and the fact that observation was limited to a very short period of seasons, and that, especially, the measurements were only made at the stationary echoes, more observation is needed for further discussion of $\alpha$.

The number of samples integrated is affected by the bandwidth of the amplifier and time interval between pulses, as well as the number of pulses which are added. There are some other causes which will theoretically affect the number of integrations. In case of PPI scanning, the illuminated volume of space should not be changed during the integrating period. The radar which was used for the experiments has a beam width of $3^{\circ}$ and antenna rotating speed of $1 \mathrm{rev} . / 15 \mathrm{sec}$. The time required for $10 \%$ of illuminated volume to be replaced is 0.015 second. As this is about the same as the time interval of $T_{0}$, as long as the rotating speed of this order or lower is used the effect of antenna rotation will be included in the factor $\alpha$. Changing the transmitting frequency will also affect the independency of the echo intensities, but this effect can be assumed to be very small and may be neglected.

\section{Conclusion}

As long as a logarithmic I.F. amplifier is used, a) the averaged signal output of a very large number of samples will be about $2.5 \mathrm{db}$ lower, and b) the threshold value of the leveling circuit for non-averaged signals will be about $6 \mathrm{db}$ higher, than the mean intensity $\bar{P}_{0}$ calculated from the radar equation. The average of several independent samples will fall between these two quantities. The optimum integrating number may be determined by the prerequisite range of fluctuation which is summarized in Fig. 5, and by the radar characteristics such as the antenna rotating speed, pulse recurrence frequencies, beam width, and the pulse duration. The integrated video signal will have very sharp contours which will prove more accurate values about the radar rainfall measurements.

Acknowledgements- The author wishes to express his gratitude to Dr. P. M. Austin and Dr. A. Fleisher. He is also indebted to a number of members of the Weather Radar section of M.I.T.

\section{References}

Austin, P. M., 1952: A study of the amplitude distribution function for radar echoes from precipitation. Weather Radar Research Technical Report No. 17, M.I.T.

Kodatra, N., 1957: An iso-echo contouring device. Proceedings Sixth Weather Radar Conference. p. 307. 
LAWson, J. L. and UHLENBECK, G. E., 1950: Threshold signals. Radiation Laboratory Series 24, McGraw-Hill Book Co., p. 53.

Stone, M. L. and Fueisher, A., 1956: The measurement of weather noise. Weather Radar Research Technical Report No. 26, M.I.T.

WALYACE, P. R., 1953: Interpretation of the fluctuating echo from randomly distributed scatterers II. Canadian Journal of Physics, 31, p. 995.

Williams, E. L., 1949: The pulse integrator. Part A-Description of the instrument and its circuitry. Weather Radar Research Technical Report No. 8A. M.I.T.

\title{
対数特性受信機及び映像平均装置を用いた気象レーダの特性について
}

\author{
小平信楌
}

多くの降水粒子からの反射波の合成値であるレーダェューはとの成分である雨㴜の運動飞より,早い変動 を示して郝り強度测定飞於ける一つの不確定さの原因となつている。従つて映像信号を平均することによ り正確な強度测定が可能である。本諭文では対数特性受信機の出力を平均した場合, その平均值が Radar 方程式より計算した值に対して平均するサムプルの数が十分大きい時は $-2.5 \mathrm{db}$ ，平均しない時一定レベ ルで切つた場合は $+6 \mathrm{db}$ の値となり, 数個平均する場合はとの数従つてこれらの間の值をとることを示 した。㕛水晶遅延回路を用いた平均装置及びその結果とついて簡単飞説明した。 